\title{
Analysis of PI3K pathway components in human cancers
}

\author{
JAMILA DARAGMEH $^{1}$, WASEIM BARRIAH ${ }^{2}$, BASHAR SAAD ${ }^{1,2}$ and HILAL ZAID ${ }^{1,2}$ \\ ${ }^{1}$ Faculty of Arts and Sciences, The Arab American University - Jenin, Jenin 11184, Palestine; \\ ${ }^{2}$ Qasemi Research Center, Al-Qasemi Academic College of Education, Baqa El-Gharbia 30100, Israel
}

Received March 18, 2015; Accepted February 16, 2016

DOI: $10.3892 / 01.2016 .4309$

\begin{abstract}
Recent advances in genomics, proteomics, cell biology and biochemistry of tumors have revealed new pathways that are aberrantly activated in numerous cancer types. However, the enormous amount of data available in this field may mislead scientists in focused research. As cancer cell growth and progression is often dependent upon the phosphoinositide 3-kinase (PI3K)/AKT pathway, there has been extensive research into the proteins implicated in the PI3K pathway. Using data available in the Human Protein Atlas database, the current study investigated the expression of 25 key proteins that are known to be involved with PI3K pathway activation in a distinct group of 20 cancer types. These proteins are AKTIP, ARP1, BAD, GSK3A, GSK3B, MERTK-1, PIK3CA, PRR5, PSTPIP2, PTEN, FOX1, RHEB, RPS6KB1, TSC1, TP53, BCL2, CCND1, WFIKKN2, CREBBP, caspase-9, PTK2, EGFR, FAS, CDKN1A and XIAP. The analysis revealed pronounced expression of specific proteins in distinct cancer tissues, which may have the potential to serve as targets for treatments and provide insights into the molecular basis of cancer.
\end{abstract}

\section{Introduction}

Phosphoinositide 3-kinases (PI3Ks) are an evolutionarily conserved family of lipid kinases that promote various cellular functions, including cell growth, metabolism and survival $(1,2)$. The lipid second messengers that are generated in this reaction interact with specialized lipid-binding domains that are present in a wide variety of signaling molecules. PI3Ks may be classified into one of three classes, each of which possesses different structures and characteristics (3). The PI3K pathway may be activated by upstream receptor tyrosine kinases, leading to the generation of phosphatidylinositol-3,4,5-trisphosphate $\left(\mathrm{PIP}_{3}\right)$ via the phosphorylation of phosphatidylinositol-4,5-bisphosphate. The phosphatase and tensin homolog (PTEN) may dephosphorylate $\mathrm{PIP}_{3}$, which terminates $\mathrm{PI} 3 \mathrm{~K}$ signaling. The accumulation

Correspondence to: Dr Hilal Zaid, Faculty of Arts and Sciences, The Arab American University - Jenin, P.O. Box 240, Jenin 11184, Palestine

E-mail: hilal.zaid@aauj.edu/hilalz@qsm.ac.il

Key words: cancer, tumorigenesis, Human Protein Atlas, PI3K, AKT, TSC1, EGFR, PTEN of $\mathrm{PIP}_{3}$ activates a signaling cascade, commencing with the phosphorylation (activation) of the protein serine-threonine kinase AKT (also known as protein kinase B) at threonine 308 by phosphoinositide-dependent kinase 1. Activation of AKT serves a crucial role in essential cellular functions, including cell proliferation and survival, via the phosphorylation of a variety of substrates (Fig. 1) (4).

Although the PI3K/AKT pathway has been extensively investigated in detail in distinct in vitro and in vivo systems (5), its role in molecular targeted therapy for cancer required further study. Molecular targeted therapies (e.g. inhibitors of target molecules with critical roles in tumor growth and progression) have been investigated in various cancer models, particularly hematological malignancies, such as leukemia, lymphoma and myeloma, due to the ease in obtaining samples for examination (6). The PI3K/AKT pathway has been reported to be activated in numerous types of malignancy (7), and inhibitors associated with this pathway have been shown to induce apoptosis in targeted tumor cells (8).

Aberrant activation of the PI3K pathway may promote carcinogenesis and tumor angiogenesis $(9,10)$. For example, a previous study reported that $\sim 30 \%$ of breast cancer cases demonstrated activating missense mutations of phosphatidylinositol-4,5-bisphosphate 3-kinase, catalytic subunit $\alpha$ (PIK3CA), the gene encoding the catalytic p110 $\alpha$ subunit of class I PI3K (2); this mutated gene provides cells with a growth advantage and promotes tumorigenesis (11). In addition, dysregulated PI3K pathway signaling has been implicated in conferring resistance to conventional therapies, including biologics, hormonal therapy, tyrosine kinase inhibitors, radiation and cytotoxic drugs in breast cancer, glioblastoma and non-small cell lung cancer (12).

Wet laboratory research has revealed enormous data in the field of cancer research, and expression levels of certain proteins can be found at the Human Protein Atlas (www.proteinatlas.org). However, these proteins are not classified according to a specific disease or disorder. The aim of the present study was to utilize data deposited in the Human Protein Atlas to investigate the protein expression level of 25 proteins that are known to be implicated in the PI3K pathway in various cancer tissues. The proteins investigated were as follows: AKTIP, ARP1, BAD, GSK3A, GSK3B, MERTK-1, PIK3CA, PRR5, PSTPIP2, PTEN, FOX1, RHEB, RPS6KB1, TSC1, TP53, BCL2, CCND1, WFIKKN2, CREBBP, capase-9, PTK2, EGFR, FAS, CDKN1A and XIAP. The analysis reveals a pronounced expression of specific proteins in distinct cancer tissues, which may be potential targets for cancer treatment and provide insights into the molecular basis of cancer. 


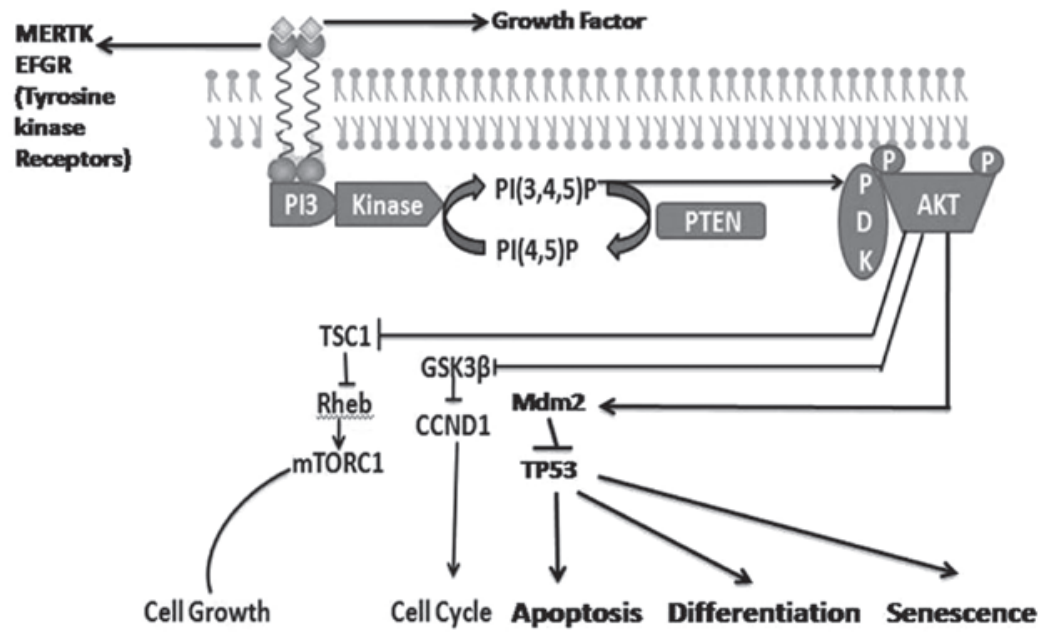

Cytoplasm

Figure 1. PI3K/AKT signaling pathway. Binding of the ligand to membrane receptor tyrosine kinases activates PI3K, which phosphorylates PIP ${ }_{2}$ to produce $\mathrm{PIP}_{3}$. PIP $\mathrm{P}_{3}$ recruits PDK1 to the plasma membrane. PDK1 phosphorylates and activates AKT, which regulates various cellular processes. The lipid phosphate activity of cytoplasmic PTEN dephosphorylates PIP $_{3}$, thereby decreasing PIP $_{3}$ levels and increasing levels of PIP $_{2}$, resulting in a concomitant decrease in AKT activity. PI3K, phosphoinositide 3-kinase; AKT, protein kinase B; $\mathrm{PIP}_{2}[\mathrm{PI}(4,5) \mathrm{P}]$, phosphatidylinositol 4,5-bisphosphate; $\mathrm{PIP}{ }_{3}[\mathrm{PI}(3,4,5) \mathrm{P}]$, phosphatidylinositol (3,4,5)-trisphosphate; PDK1, phosphoinositide-dependent kinase 1; PTEN, phosphatase and tensin homolog.

\section{Materials and methods}

Data were collected from the Human Protein Atlas database (www.proteinatlas.org) via manual searches of the desired gene names. The expression levels of 25 specific proteins that are known to be involved in the PI3K pathway were investigated in 20 different cancer tissues types: Carcinoid, glioma, liver cancer, lymphoma, melanoma, ovarian cancer, pancreatic cancer, skin cancer, testis, urothelial, lung cancer, breast cancer, cervical cancer, colorectal cancer, head and neck, renal, thyroid, prostate, endometrial and stomach cancer.

The expression of the 25 proteins in the different cancer tissues were reported as high, medium or low (excluding no expression, which was considered as a separate category) relative to normal tissues as shown in the database. Thereafter, the percentage of high, medium and low expression in each tissue type was calculated by dividing the number of patients exhibiting high expression, for example, over the total number of patients in the sample for each tissue type. The number of patients per sample ranged from 8-18. Furthermore, high and medium percentages were combined as the biological impact of high and medium expression was believed to be similar. Graphs were created using Microsoft Excel 12.0 (Microsoft Corporation, Redmond, WA, USA) to represent the percentage of each level of protein expression as it was expressed in these patients.

\section{Results and Discussion}

In this study, the expression levels of 25 proteins in tissues from 20 cancer types were analyzed utilizing the Human Protein Atlas (www.proteinatlas.org). The following proteins examined: AKTIP, ARP1, BAD, GSK3A, GSK3B, MERTK-1, PIK3CA, PRR5, PSTPIP2, FOX1, RHEB, TSC1, TP53, BCL2, CCND1, WFIKKN2, CREBBP, RPS6KB1, caspase-9, EGFR, PIK2, FAS, CDKN1A, XIAP and PTEN. The physiological

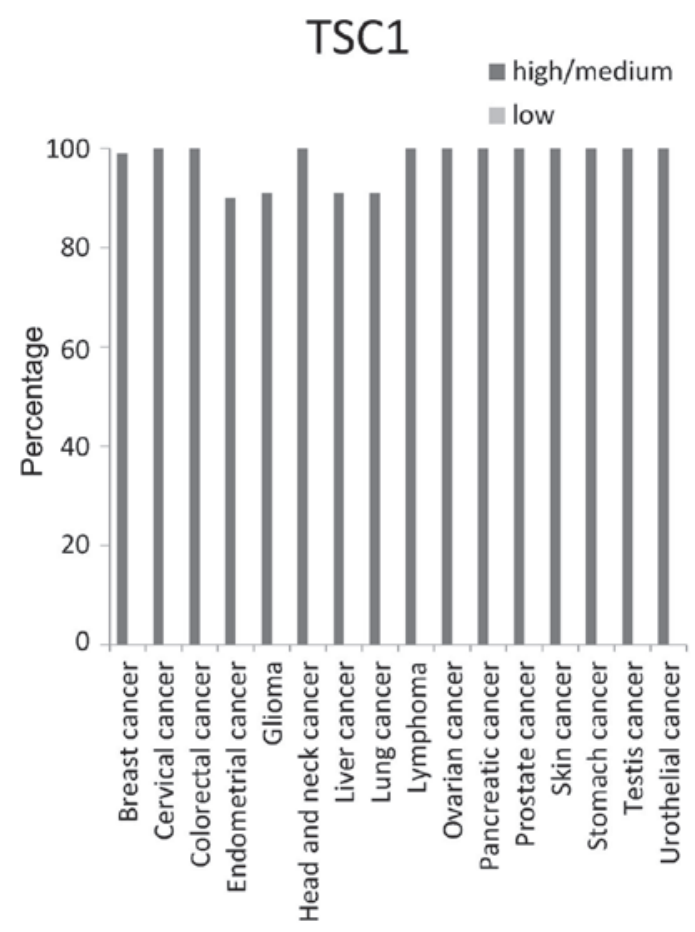

Figure 2. Expression levels of tuberous sclerosis 1 (TSC1) protein in different cancer tissues based on Human Protein Atlas.

activity and full name of these proteins, as well as their role in cancer initiation and control, is summarized in Table I (13-43).

The results revealed that 9 of the 25 proteins tested exhibited high expression levels in various cancer tissues. These proteins were PIK3CA, RPS6KB1, MERTK, RHEB, EGFR, TSC1, CCND1, TP53 and PTEN. The other 16 proteins exhibited low or no expression in tumor tissues (data not shown).

The expression level for each protein tested was categorized as either high/medium or low. The protein TSC1 


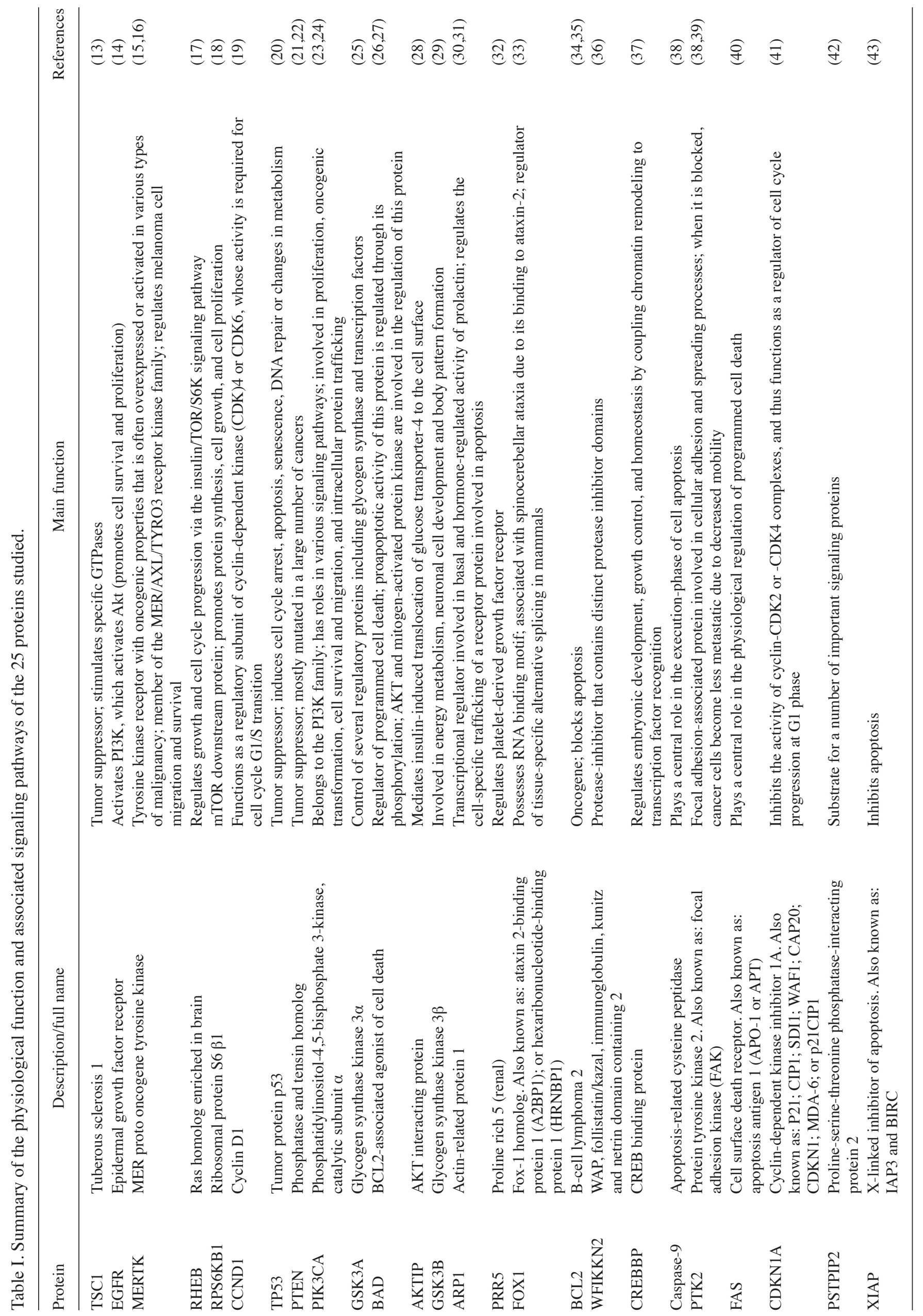




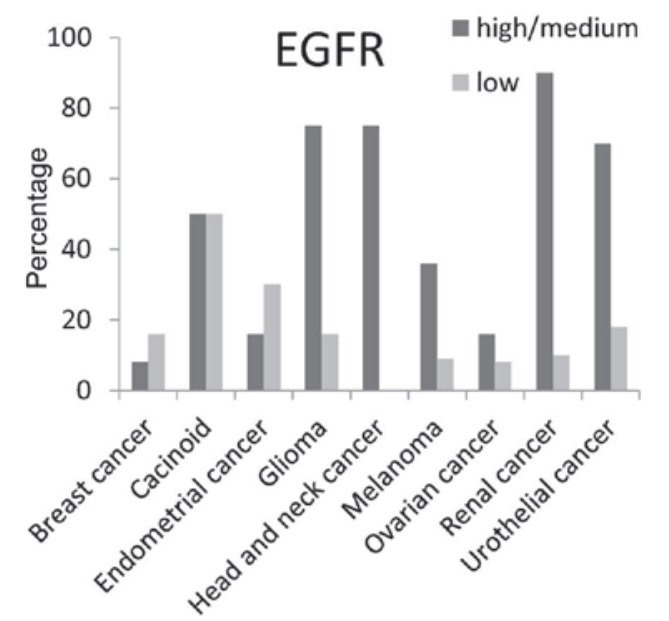

Figure 3. Expression percentages of epidermal growth factor receptor (EGFR) protein in 10 different cancer tissues based on Human Protein Atlas.

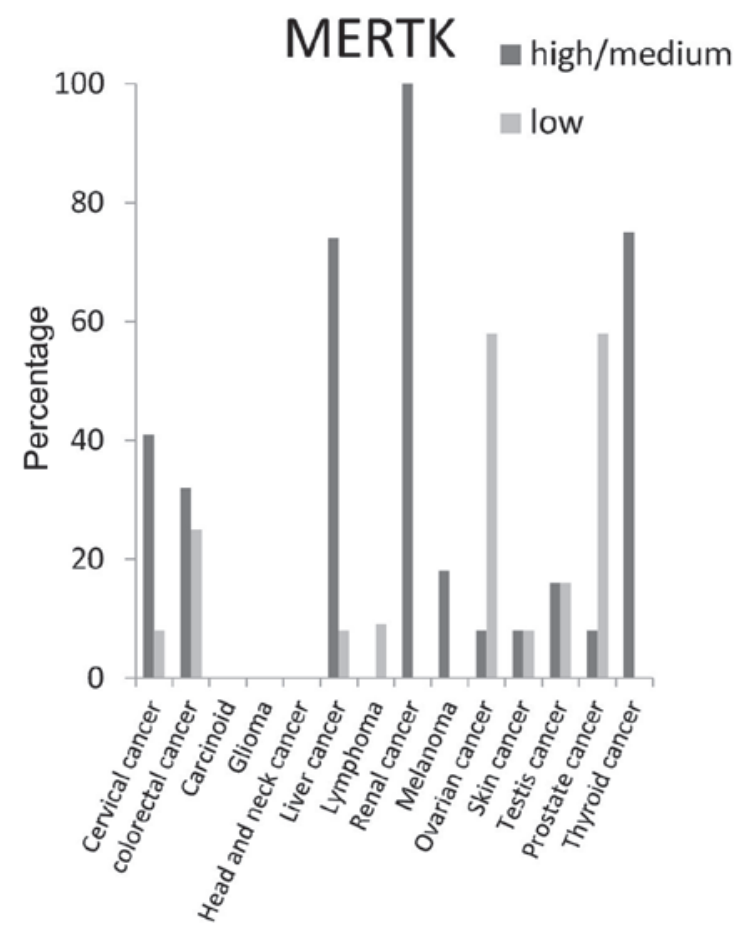

Figure 4. Expression percentages of MER proto oncogene tyrosine kinase (MERTK) protein in different cancer tissues based on Human Protein Atlas.

exhibited high/medium expression in all types of cancer tissue tested. TSC1 exhibited $\sim 100 \%$ high/medium expression in breast, cervical, colorectal, head and neck, lymphoma, ovarian, pancreatic, prostate, skin, stomach, testis and urothelial cancer tissues. It expression was $\sim 90 \% \mathrm{high} /$ medium in endometrial, glioma, liver and lung cancers (Fig. 2).

EGFR protein had high/medium expression level in $>50 \%$ of carcinoid, head and neck, glioma, renal and urothelial cancer tissues (Fig. 3). For MERTK protein the high/medium expression rate was $>50 \%$ in liver and thyroid cancer tissues, and $100 \%$ in renal cancer tissues. It was not detected in carcinoid, glioma, or head and neck cancer tissues (Fig. 4).

For RHEB protein, the highest expression level was present in $>50 \%$ of breast, endometrial, ovarian, pancreatic

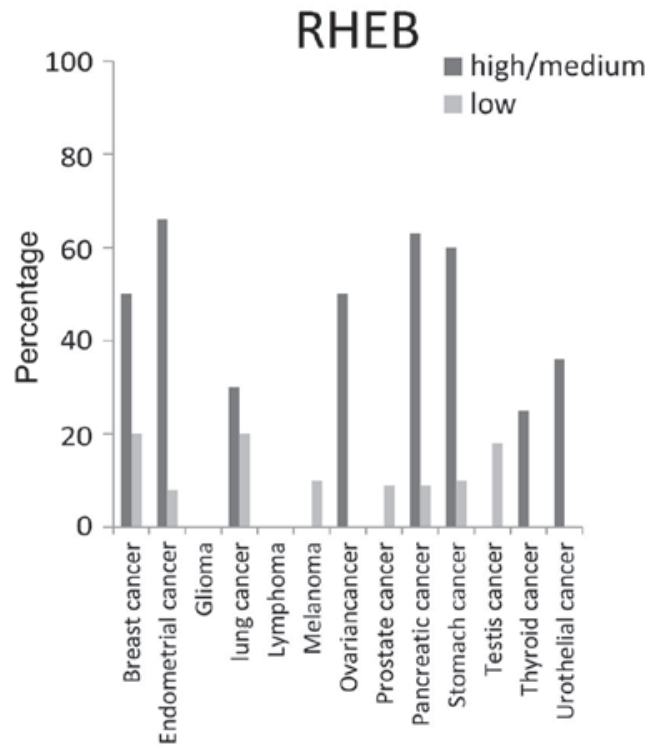

Figure 5. Expression percentages of Ras homolog enriched in brain (RHEB) protein in different cancer tissues based on Human Protein Atlas.

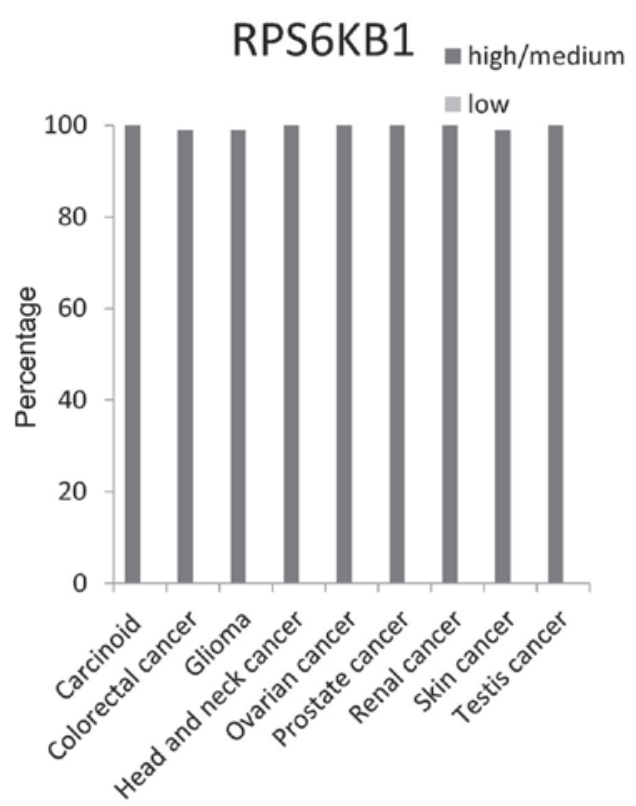

Figure 6. Expression percentages of ribosomal protein S6 $\beta 1$ (RPS6KB1) protein in different cancer tissues based on Human Protein Atlas.

and stomach cancer tissues, but was not detected in glioma and lymphoma cancer tissues (Fig. 5).

The RPS6KB1 protein expression level had $100 \%$ high/medium in 9 cancer tissue tested: Carcinoid, colorectal, glioma, head and neck, ovarian, prostate, renal, skin and testis cancer tissues (Fig. 6).

CCND1 protein high/medium expression level was present in $\sim 50 \%$ of head and neck cancer and melanoma tissues (Fig. 7). The high/medium expression percentage of TP53 protein was $\geq 50 \%$ in colorectal, head and neck, ovarian, pancreatic and urothelial tissues, but was not detected at all in carcinoid, prostate and thyroid cancer tissues (Fig. 8).

The expression level of PTEN protein (a tumor suppressor gene) was low in various cancer tissues as was expected. 


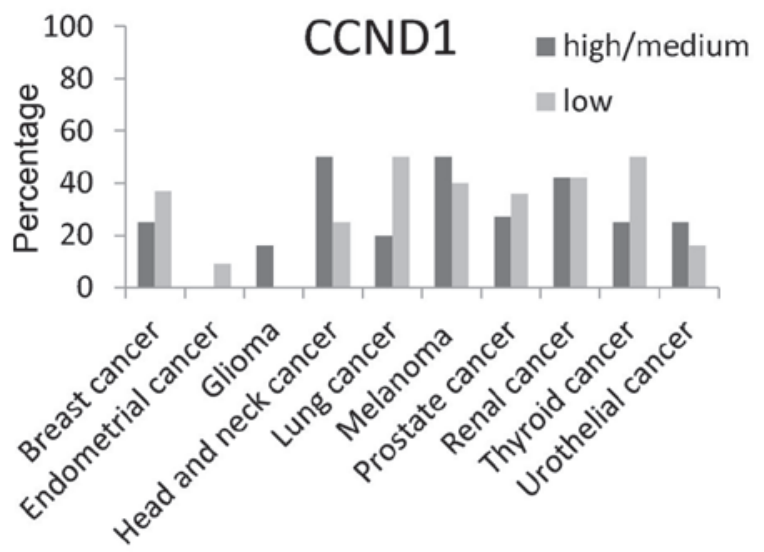

Figure 7. Expression percentages of Cyclin D1 (CCND1) protein in different cancer tissues based on Human Protein Atlas.

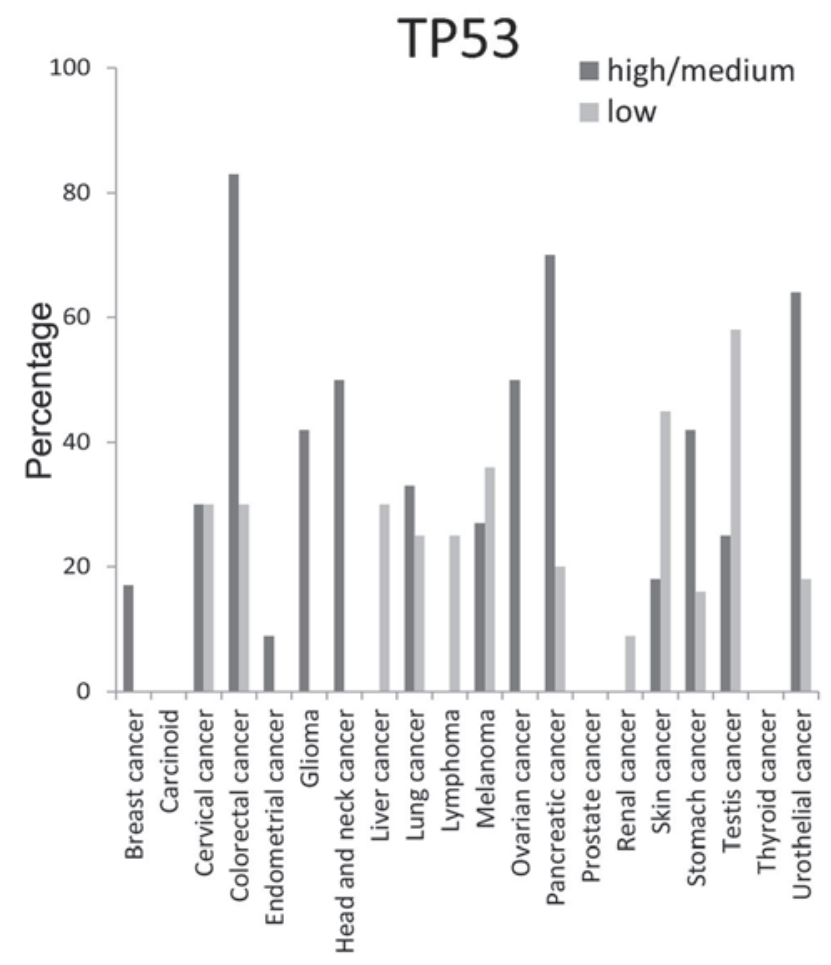

Figure 8. Expression percentages of tumor protein p53 (TP53) in different cancer tissues based on Human Protein Atlas.

A high/medium PTEN expression level was present in $<50 \%$ of breast, cervical, endometrial, glioma, head and neck, liver, pancreatic and skin cancer tissues; however, high/medium expression was present at a rate of $\sim 75 \%$ in melanoma (Fig. 9).

PIK3CA protein expression level was high/medium in around $100 \%$ of lymphoma, ovarian and pancreatic cancer tissues, $90 \%$ of liver cancer tissues, $85 \%$ of melanoma and prostate cancer tissues, $70 \%$ of carcinoid and stomach cancer tissues and $65 \%$ of cervical cancer tissues (Fig. 10).

Taking this data together, the current analysis reveals a pronounced expression of specific proteins in distinct cancer tissues. These proteins may be potential candidates to serve as targets for cancer treatments and provide insights into the molecular basis of cancer. PI3Ks initiate signaling

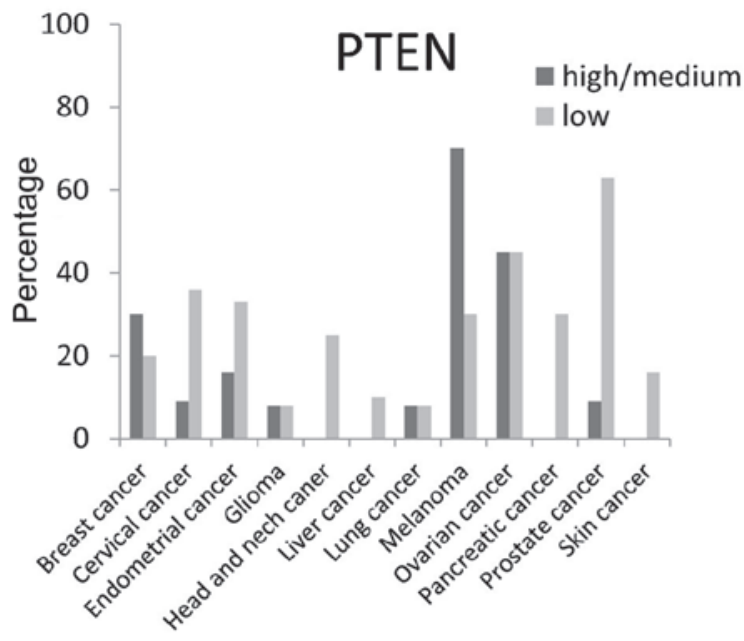

Figure 9. Expression percentages of phosphatase and tensin homolog (PTEN) protein (tumor suppressor gene) based on Human Protein Atlas.

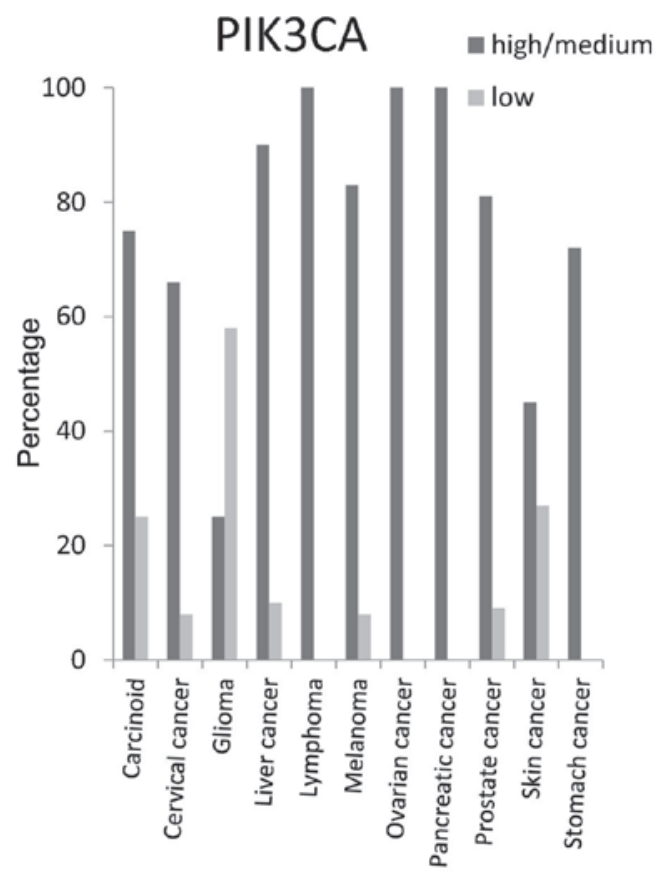

Figure 10. Expression percentage of phosphatidylinositol-4,5-bisphosphate 3-kinase, catalytic subunit $\alpha$ (PIK3CA) protein based on Human Protein Atlas.

through a network of downstream effector pathways. Due to the direct implication of the pathway in numerous cancer types, this pathway has become the target for novel cancer therapies. This bird's-eye view study highlights 9 proteins that are involved in the PI3K pathway and which may be potential targets for cancer treatment. These proteins are highly expressed in several cancer tissues as indicated. Designing new drugs that modulate the activity of these proteins may decrease cancer growth, migration and metastasis.

\section{Acknowledgements}

This study was supported by Alqasemi Research Fund and the Association of Arab Universities Research Fund. 


\section{References}

1. Cantley LC: The phosphoinositide 3-kinase pathway. Science 296: $1655-1657,2002$

2. Vogelstein B and Kinzler KW: Cancer genes and the pathways they control. Nat Med 10: 789-799, 2004.

3. Akinleye A, Avvaru P, Furqan M, Song Y and Liu D: Phosphatidylinositol 3-kinase (PI3K) inhibitors as cancer therapeutics. J Hematol Oncol 6: 88, 2013.

4. Ocana A, Vera-Badillo F, Al-Mubarak M, Templeton AJ Corrales-Sanchez V, Diez-Gonzalez L, Cuenca-Lopez MD, Seruga B, Pandiella A and Amir E: Activation of the $\mathrm{PI} 3 \mathrm{~K} / \mathrm{mTOR} / \mathrm{AKT}$ pathway and survival in solid tumors: Systematic review and meta-analysis. PLoS One 9: e95219, 2014

5. Ott PA and Adams S: Small-molecule protein kinase inhibitors and their effects on the immune system: Implications for cancer treatment. Immunotherapy 3: 213-227, 2011.

6. Kummar S, Kinders R, Gutierrez ME, Rubinstein L, Parchment RE, Phillips LR, Ji J, Monks A, Low JA, Chen A, et al: Phase 0 clinical trial of the poly (ADP-ribose) polymerase inhibitor ABT-888 in patients with advanced malignancies. J Clin Oncol 27: 2705-2711, 2009.

7. Fresno Vara JA, Casado E, de Castro J, Cejas P, Belda-Iniesta C and González-Barón M: PI3K/Akt signalling pathway and cancer. Cancer Treat Rev 30: 193-204, 2004.

8. Wilson JM, Kunnimalaiyaan S, Kunnimalaiyaan M and Gamblin TC: Inhibition of the AKT pathway in cholangiocarcinoma by MK2206 reduces cellular viability via induction of apoptosis. Cancer Cell Int 15: 13, 2015.

9. Osaki M, Oshimura M and Ito H: PI3K-Akt pathway: Its functions and alterations in human cancer. Apoptosis 9: 667-676, 2004.

10. Patel S: Exploring novel therapeutic targets in GIST: Focus on the PI3K/Akt/mTOR pathway. Curr Oncol Rep 15: 386-395, 2013.

11. Liu P, Cheng H, Roberts TM and Zhao JJ: Targeting the phosphoinositide 3-kinase pathway in cancer. Nat Rev Drug Discov 8 : 627-644, 2009

12. Samuels Y, Wang Z, Bardelli A, Silliman N, Ptak J, Szabo S, Yan H, Gazdar A, Powell SM, Riggins GJ, et al: High frequency of mutations of the PIK3CA gene in human cancers. Science 304 $554,2004$.

13. Demetriades C, Doumpas N and Teleman AA: Regulation of TORC1 in response to amino acid starvation via lysosomal recruitment of TSC2. Cell 156: 786-799, 2014

14. Yewale C, Baradia D, Vhora I, Patil S and Misra A: Epidermal growth factor receptor targeting in cancer: A review of trends and strategies. Biomaterials 34: 8690-8707, 2013.

15. Schlegel J, Sambade MJ, Sather S, Moschos SJ, Tan AC, Winges A, DeRyckere D, Carson CC, Trembath DG, Tentler JJ, et al: MERTK receptor tyrosine kinase is a therapeutic target in melanoma. J Clin Invest 123: 2257-2267, 2013.

16. Cummings CT, DeRyckere D, Earp HS and Graham DK: Molecular pathways: MERTK signaling in cancer. Clin Cancer Res 19: 5275-5280, 2013

17. Karassek S, Berghaus C, Schwarten M, Goemans CG, Ohse N, Kock G, Jockers K, Neumann S, Gottfried S, Herrmann C, et al: Ras homolog enriched in brain (Rheb) enhances apoptotic signaling. J Biol Chem 285: 33979-33991, 2010.

18. Du W, Gerald D, Perruzzi CA, Rodriguez-Waitkus P, Enayati L, Krishnan B, Edmonds J, Hochman ML, Lev DC and Phung TL: Vascular tumors have increased p70 S6-kinase activation and are inhibited by topical rapamycin. Lab Invest 93: 1115-1127, 2013.

19. Juskevicius D, Ruiz C, Dirnhofer S and Tzankov A: Clinical, morphologic, phenotypic and genetic evidence of cyclin D1-positive diffuse large B-cell lymphomas with cyclin D1 gene rearrangements. Am J Surg Pathol 38: 719-727, 2014.

20. Hejnold M, Dyduch G, Białas M, Demczuk S, Ryś J, Chłosta P, Szopiński T and Okoń K: Selected immunohistochemical features of conventional renal cell carcinomas coexpressing P53 and MDM2. Pol J Pathol 65: 113-119, 2014

21. Wang H, Chen P, Liu XX, Zhao W, Shi L, Gu XW, Zhu CR, Zhu HH and Zong L: Prognostic impact of gastrointestinal bleeding and expression of PTEN and Ki-67 on primary gastrointestinal stromal tumors. World J Surg Oncol 12: 89, 2014

22. Luo J, Manning BD and Cantley LC: Targeting the PI3K-Akt pathway in human cancer: Rationale and promise. Cancer Cell 4: 257-262, 2003.

23. Qiu W, Tong GX, Turk AT, Close LG, Caruana SM and Su GH Oncogenic PIK3CA mutation and dysregulation in human salivary duct carcinoma. Biomed Res Int 2014: 810487, 2014.
24. Cho DC: Targeting the PI3K/Akt/mTOR pathway in malignancy: Rationale and clinical outlook. BioDrugs 28: 373-381, 2014.

25. Li X and Jope RS: Is glycogen synthase kinase-3 a central modulator in mood regulation? Neuropsychopharmacology 35 : 2143-2154, 2010

26. Huang N, Zhu J, Liu D, Li YL, Chen BJ, He YQ, Liu K, Mo XM and Li WM: Overexpression of Bcl-2-associated death inhibits A549 cell growth in vitro and in vivo. Cancer Biother Radiopharm 27: 164-168, 2012.

27. Cooray S: The pivotal role of phosphatidyl inositol 3-kinase-Akt signal transduction in virus survival. J Gen Virol 85: 1065-1076, 2004.

28. Yang F, Deng R, Qian XJ, Chang SH, Wu XQ, Qin J, Feng GK, Ding K and Zhu XF: Feedback loops blockade potentiates apoptosis induction and antitumor activity of a novel AKT inhibitor DC120 in human liver cancer. Cell Death Dis 5: e1114, 2014

29. Taelman VF, Dobrowolski R, Plouhinec JL, Fuentealba LC, Vorwald PP, Gumper I, Sabatini DD and De Robertis EM: Wnt signaling requires sequestration of gycogen synthase kinase 3 inside multivesicular endosomes. Cell 143: 1136-1148, 2010.

30. Wang J, Xin YF, Xu WJ, Liu ZM, Qiu XB, Qu XK, Xu L, Li X and Yang YQ: Prevalence and spectrum of PITX2c mutations associated with congenital heart disease. DNA Cell Biol 32: 708-716, 2013

31. Símová S, Klíma M, Cermak L, Sourková V and Andera L: Arf and Rho GAP adapter protein ARAP1 participates in the mobilization of TRAIL-R1/DR4 to the plasma membrane. Apoptosis 13: 423-436, 2008.

32. Gan X, Wang J, Wang C, Sommer E, Kozasa T, Srinivasula S, Alessi D, Offermanns S, Simon MI and Wu D: PRR5L degradation promotes mTORC2-mediated PKC-delta phosphorylation and cell migration downstream of $\mathrm{G} \alpha 12$. Nat Cell Biol 14: 686-696, 2012

33. Kuroyanagi H: Fox-1 family of RNA-binding proteins. Cell Mol Life Sci 66: 3895-3907, 2009.

34. Greenberg EF, Lavik AR and Distelhorst CW: Bcl-2 regulation of the inositol 1,4,5-trisphosphate receptor and calcium signaling in normal and malignant lymphocytes: Potential new target for cancer treatment. Biochim Biophys Acta 1843: 2205-2210, 2014

35. Bose P, Rahmani M and Grant S: Coordinate PI3K pathway and Bcl-2 family disruption in AML. Oncotarget 3: 1499-1500, 2012.

36. Szlama G, Trexler M and Patthy L: Latent myostatin has significant activity and this activity is controlled more efficiently by WFIKKN1 than by WFIKKN2. FEBS J 280: 3822-3839, 2013

37. Kim MS, Yoo NJ and Lee SH: Expressional and mutational analysis of CREBBP gene in gastric and colorectal cancers with microsatellite instability. Pathol Oncol Res 20: 221-222, 2014.

38. Unno H, Futamura K, Morita H, Kojima R, Arae K, Nakae S, Ida H, Saito H, Matsumoto K and Matsuda A: Silica and double-stranded RNA synergistically induce bronchial epithelial apoptosis and airway inflammation. Am J Respir Cell Mol Biol 51: 344-353, 2014.

39. Lackie JM, Coote JG and Lloyd CW (eds): The Dictionary of Cell \& Molecular Biology. 5th edition. Academic Press, San Diego, CA, 2013

40. Villa-Morales M, Cobos MA, González-Gugel E, Álvarez-Iglesias V, Martínez B, Piris MA, Carracedo A, Benítez J and Fernández-Piqueras J: FAS system deregulation in T-cell lymphoblastic lymphoma. Cell Death Dis 5: e1110, 2014.

41. Gupta R, Dong Y, Solomon PD, Wettersten HI, Cheng CJ, Min JN, Henson J, Dogra SK, Hwang SH, Hammock BD, et al: Synergistic tumor suppression by combined inhibition of telomerase and CDKN1A. Proc Natl Acad Sci USA 111: E3062-E3071, 2014

42. Thapa N and Anderson RA: PIP2 signaling, an integrator of cell polarity and vesicle trafficking in directionally migrating cells. Cell Adh Migr 6: 409-412, 2012.

43. Miyamoto M, Takano M, Iwaya K, Shinomiya N, Kato M, Aoyama T, Sasaki N, Goto T, Suzuki A, Hitrata J and Furuya K: $\mathrm{X}$-chromosome-linked inhibitor of apoptosis as a key factor for chemoresistance in clear cell carcinoma of the ovary. Br J Cancer 110: 2881-2886, 2014. 